\title{
THE ROLE OF BIOREFINERING RESEARCH IN THE DEVELOPMENT OF A MODERN BIOECONOMY
}

\author{
Paloma Manzanares \\ Biofuels Unit. Renewable Energies Division. Centre for Research on Energy, Technology and Environment \\ (CIEMAT) \\ Avda. Complutense 40, 28040 Madrid, Spain, p.manzanares@ciemat.es \\ (Dhttps://orcid.org/0000-0001-7735-4796
}

\begin{abstract}
The current economy system is based in an intensive consumption of fossil fuels in a way that severely compromise future of the planet due to the severe consequences in climate change. In this scenario, the development of flexible and integrated biorefineries to produce biofuels and bioproducts from renewable biomass sources represent a key tool to perform the transition from a petroleum-based economy to a novel bioeconomy that looks for a more efficient and sustainable global development. This article analyses: the significance of biomass sources (such as agricultural and woody crops and residues, agro-food and wood processing industries residues and urban wastes) as feedstocks in the biorefinery, the most relevant biorefinering process technologies of the biochemical and thermochemical conversion pathways that are nowadays under development, and the need of further research and innovation effort to eventually achieve the commercialization and application in the market of the different biorefinery products.
\end{abstract}

\section{Keywords}

biomass; bioenergy; bioproduct; circular economy

\section{Introduction}

Bioeconomy is a relatively recent concept that arises as a reaction to the intensive development in the presentday society of an economy based on fossil fuels, in a way that severely compromises an efficient and sustainable use of natural resources. As a concept still under development, there is no consensus on the definition of a bioeconomy and several meanings can be found in the literature. For example, according to OECD [1], bioeconomy should involve three major elements: biotechnological knowledge, renewable biomass and integration across applications. In this definition, the second element refers to the use of renewable biomass and efficient bioprocesses to achieve sustainable production, with renewable feedstocks being obtained from primary biomass sources or wastes derived from household, industrial and agricultural activities. According to the European Commission, "bioeconomy comprises those parts of the economy that use renewable biological resources from land and sea - such as crops, forest, fish, animals, and micro-organisms - to produce food, feed, fibre, bio-based materials and energy", as stated in the European Bioeconomy Strategy launched in 2012 [2]. In the same line, the US Department of Energy [3] defines bioeconomy as "the global industrial transition of sustainably utilizing renewable aquatic and terrestrial biomass resources in energy, intermediate, and final products for economic, environmental, social, and national security benefits". In the opinion of the US National Academies of Sciences, Engineering and Medicine [4], a fundamental challenge in defining a bioeconomy is that it is not a single economic sector or grouping of sectors. A general consensus exists on bioeconomy contributes to the overall economy sustainability by implying a great number of industries and services in this new economic model.

It is an unquestionable fact that natural resources available for world's population are finite. The society is currently facing a series of environmental and social challenges such as the growth of world population, the climate change and the degradation of ecosystems that require the definition of new production and consumption pathways that are sustainable from the economic, social and environmental point of view. In this context, bioeconomy can provide a clear response by contributing to an equitable supply and distribution of food, the mitigation of climatic change effects and the reduction of the use of fossil fuels. Moreover, it can open new opportunities for economy development and employment.

The European Commission approved last year the European Green Deal Action Plan to face the challenges that the fulfilment of the goals assumed by world leaders in the 2030 Agenda for Sustainable Development involve [5]. The plan aims at making the EU's economy sustainable by turning climate and environmental challenges into 
opportunities, and making the transition just and inclusive for all. As a key element of that plan, the EC has recently adopted a new Action Plan on Circular Economy [6] with a sustainable products initiative and a particular focus on resource intense sectors such as textiles, construction, electronics and plastics. The new Action Plan has the objective to adapt the economy to a sustainable future and reinforce competitiveness, while protecting the environment and granting new rights to the consumers. According to European Parliament's definition, the circular economy is "a model of production and consumption, which involves sharing, leasing, reusing, repairing, refurbishing and recycling existing materials and products as long as possible". In this way, the life cycle of products is extended. The circular economy in the context of bioeconomy is referred as circular bioeconomy, encompassing the fields of resources, byproducts and residues of organic nature (Fig. 1). Thus, the bioeconomy symbolizes the renewable segment of circular economy.

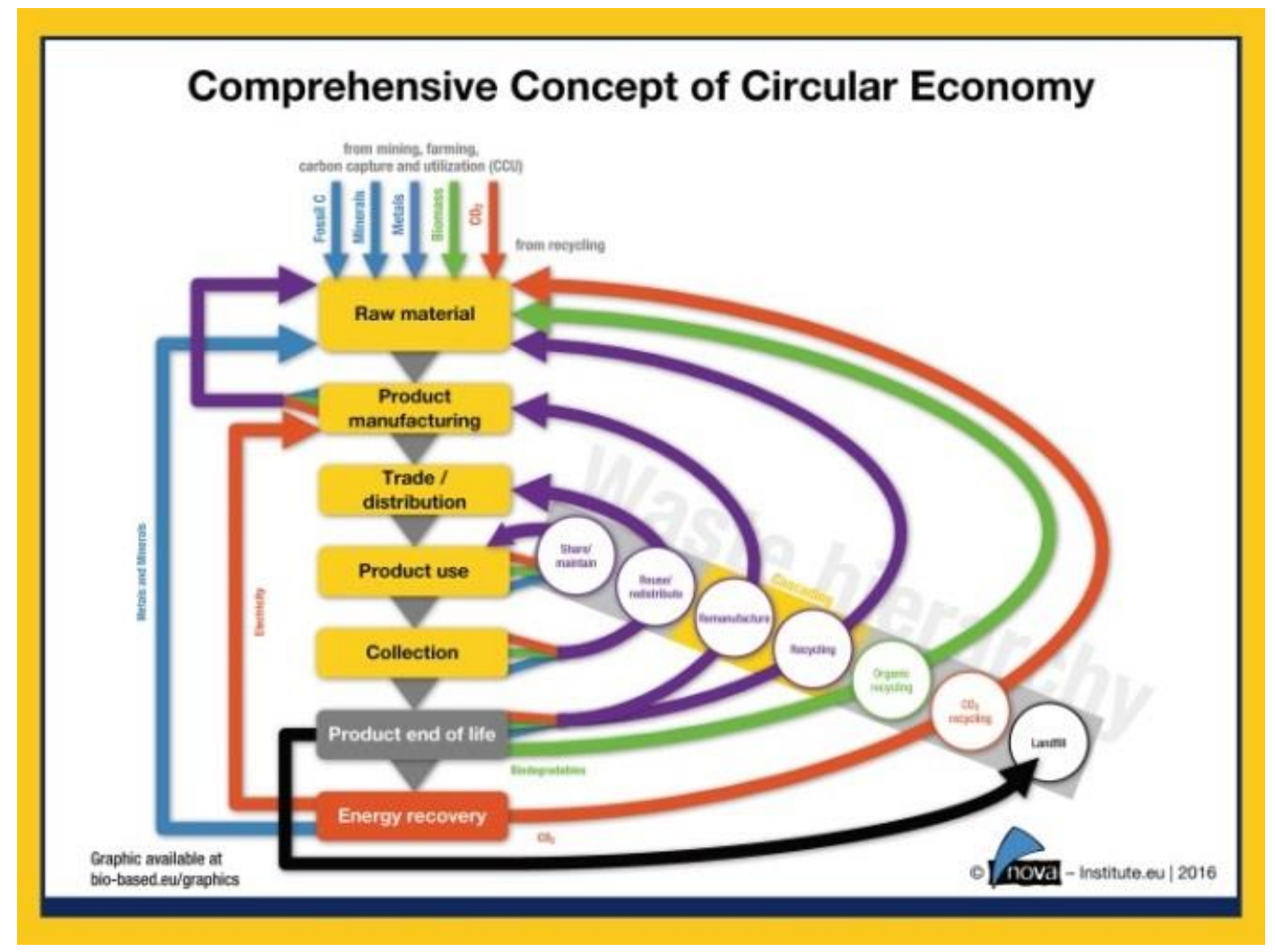

Fig. 1. Comprehensive Concept of Circular Economy. Source: nova-Institut GmbH, 2016-10-06.

One of the key enabling strategies of the circular economy is biorefinering, by closing loops of raw biomass materials (reutilization of residues from forestry, agro, processing and postconsumer activities), minerals, water and carbon. According to IEA (International Energy Agency) Bioenergy organization biorefining, "is an innovative and efficient approach to use available biomass resources for the synergistic coproduction of power, heat and biofuels alongside food and feed ingredients, pharmaceuticals, chemicals, materials, minerals and short-cyclic $\mathrm{CO}_{2}$ ". In the opinion of this organization, biorefining is the optimal strategy for large-scale sustainable use of biomass in the circular bioeconomy.

As a result of biorefinering, the production of food/feed constituents, biobased products and bioenergy will be cost-competitive while optimizing socio-economic and environmental impacts such as an efficient resources use, reduced GHG emissions, etc. Biorefinering strategy has been identified as a key element to boost emerging bioeconomy by offering a wide-range variety of products from an extensive spectrum of biomass sources to satisfy the different demands of the community [7]. In addition, biorefineries are key elements to support the development of a circular bioeconomy by connecting the stream and loops and allowing for the valorisation of multiple side-products. 
The aim of the present article is to discuss and analyse the importance of biorefinering research in the development of a real bioeconomy. Firstly, the role of biomass resource as a pillar of bioeconomy development is highlighted. Secondly, relevant process technologies in biorefinering are discussed and examples of existing biorefinery applications are given. Finally, recent innovation advances in the different fields comprised in the biorefinery concept, which are expected to contribute to biorefinery deployment, are briefly examined.

\section{Biomass in the core of the bioeconomy}

Biomass is the renewable resource that constitutes the basis of bioeconomy development. Biomass features as constant supply, wide availability, easy accessibility and production potential make this renewable feedstock a unique material source for the production of energy, fuels and bioproducts. The relevance of biomass as enewable material can be illustrated by the significance of its contribution worldwide in terms of primary energy, which the International Renewable Energy Agency (IRENA) calculates could range from 97-147 EJ/Yr by 2030 [8]. About $38-45 \%$ of the total supply is estimated to come from agricultural residues and waste, the remaining supply potential being shared between energy crops and forest products, including forestry residues.

Biomass is a broad concept that has been described in many different ways, depending on the context. Thus, it is important clearly state the framework of the term used and avoid partial [9]. For instance, in the EU Directive $2018 / 2001$ on the promotion of the use of energy from renewable sources, biomass is explained as "the biodegradable fraction of products, waste and residues from biological origin from agriculture, including vegetal and animal substances, from forestry and related industries, including fisheries and aquaculture, as well as the biodegradable fraction of waste, including industrial and municipal waste of biological origin" [10]. A more general description refers to "all organic matter existing in the biosphere, whether of plant or animal origin, as well as those materials obtained through their natural or artificial transformation" [11].

Biomass sources can be classified in relation to origin, chemical composition or biomass end use and consequently many comprehensive classifications exist [9, 12]. Relevant to the bioeconomy and biorefinery concepts, biomass feedstocks consist of current cultivated crops, such as cereals and oilseeds; dedicated biomass crops, such as woody crops; residues from agriculture (e.g. straw), agro-food or urban waste, lignocellulosic biomass from forest clean-up operations, and residues from the wood processing industry. All these biomass feedstocks have been already considered in a first approach for energy production as bioenergy is, nowadays, the main application for biomass resources worldwide. Nowadays bioeconomy offers many opportunities for integrating bioenergy applications within the biorefinery production models in order to optimize biomass resources use and maximize the generation of bio-based products. This idea is clearly supported by EU research programmes such as the Energy European Research Alliance (EERA) Bioenergy Joint Programme that, when defining the Strategic Research And Innovation Agenda (SIRA) [13], states that a "sustainable biomass feedstock must be developed within the broader framework of bioeconomy and circular economy concepts, where bioenergy is an essential part and may play a fundamental role in its deployment". Also, an interesting issue addressed in the SIRA of EERA is that exploring and making use of the potential of still underused, or even unused, biomass resources are also important aspects to satisfy the increasing future biomass demand. A good example of this type of biomass is biomass produced in shrub lands, which area in Europe has been estimated in 21 Mha [13].

Biomass feedstock, as the starting premise in the development of a bio-based economy, has a decisive role in determining the viability of any biomass processing activity, and the success will only be attained when sustainable supply of biomass can be guaranteed. To this end, it will be crucial to know what type of biomass will be necessary for each particular process application and in what quantity is needed, assessing the technical, economic and environmental viability linked to the biomass supply. Moreover, it will be necessary to identify in each case the current and future market needs to couple biomass demand and supply.

Several challenges in relation to biomass as feedstock for the production of biofuels and bioproducts have been recognised and research needs to face them identified. On the one hand, it is necessary to improve biomass productivity and yield and, for some specific biomasses, the yield of characteristic constituents (e.g. lipids, sugars, and proteins), always considering that these goals have to be achieved under sustainable conditions. To this end, it is crucial to better understand the biosynthesis and structure of the different types of biomass materials and study possibilities for engineering improved yields of polymers, oligomers, monomers and other biomass components [14]. On the other hand, aspects related to cultivation systems need to be studied to enhance yields, decrease feedstock costs and attain a sustainable biomass production. According to the EERA Bioenergy 
Programme [13], a research priority in this area would be the design and optimization of innovative systems combining different crops, particularly for agricultural biomass feedstocks.

There are other issues related with biomass availability and supply that also need research effort to reach a successful bio-based economy. Thus, it is necessary to advance in the identification; quantification and geolocation of biomass sources with advanced technologies, such as satellite imaging or remote sensing, to provide a precise biomass inventory that allows an adequate planning of biomass use. Moreover, the development and application of standardized compositional analytical techniques that permit standardization of biomass materials quality, the creation of associated composition databases and the determination of the most adequate transformation pathway, appear as main challenges to tackle in the future. It is also crucial to address aspects related with the development of advanced tools to improve the current biomass logistic models and the optimization of biomass storage and transport systems, since all these aspects will definitely have a great impact in the development of cost efficient and sustainable biomass transformation processes.

Finally, as pointed out at the beginning of this section, the sustainability of integrated biomass production and supply chains systems is essential to secure a satisfactory bio-based economy development. To reach this ambitious goal, studies that sustain well-informed resolutions by landowners, communities, businesses and governments will be needed. A fundamental objective is to intensify the knowledge of the environmental, social and economic impacts of producing and using biomass within a broad bioeconomy scenario. Environmental impacts of biomass production involve water availability and quality, soil and air quality, biodiversity, and climate through the emissions of greenhouse gases and $C$ sequestration in soils. All the different areas on biomass resource discussed above are closely related and the development of one of them also impacts on the others [14].

Biorefinery: a main element in the framework of the emerging bioeconomy

Biorefinery is not a novel concept and examples of conventional biorefieneries exist for a long time. For instance, industrial development associated with food production and pulp and paper industry represent clear examples of biorefinery applications at commercial scale. However, a broader and more advanced conception has lately emerged around this concept and nowadays biorefineries constitute a key tool for bioeconomy development, aimed at providing a wide range of product portfolio from a broad spectrum of biomass resources to fulfill the different needs of the society [15]. In a wide sense, a biorefinery can be defined as this facility that using different biomass feedstocks generates an ample range of different products (chemicals, fuels and materials). It can be considered somehow analogous to the petrochemical refinery in a "bio" base.

Since the term biorefinery involves several industrial sectors, such as transport, chemical, energy, agricultural and forestry, it seems difficult to establish a single definition and there are different classification criteria for biorefineries proposed by several authors [16-18]. Most biorefinery classification approaches are developed using principles such as their technological implementation status (advanced vs conventional), the type of biomass feedstock used (sugar, starch, lignocellulose or oil containing crops, aquatic biomass and organic residues), the main conversion process pathway (mechanical/physical, chemical, biochemical, thermochemical), the main intermediates produced ( $\mathrm{C} 5$ and $\mathrm{C} 6$ sugars, oil, biogas, syngas, lignin, etc.) that constitute the "platforms" or the products generated (energy or materials) $[15,18]$.

Due to the complexity of the biorefinery concept and the diversity of feedstocks/process/products applications, it is challenging to describe in short the precise status of each technological pathway. For instance, in the last decades an important focus in the development of biorefinery systems has been the production of energy products such as biofuels, power and heat, in the so-called energy-driven concept of biorefinery [7]. By contrast, the above cases of biorefineries associated to the pulp and mill and food industry would represent examples of product-driven biorefineries, in which the main objective is to generate a set of relatively high added-value bio-based products, in smaller quantities. Another interesting case of this type of biorefinery is the evolving biobased polymers and plastics industry (e.g., vinyl polymers, polyesters, polyamides, polyurethanes and synthetic rubbers), which shows an enormous growth potential [19].

The energy-driven biorefinery approach, based in the generation of large volumes of relatively low-cost energy from biomass, has lately evolved to the intensification of bioproducts production associated to a main energy carrier, thus enhancing the profitability of the biomass use. Moreover, the development of integrated biorefineries producing energy, biofuels, chemicals and biomaterials will provide a higher flexibility against market fluctuations and society needs. In this context, the emerging concept of bioeconomy offers many 
opportunities for integrating bioenergy technologies within the biorefinery production models in order to increase the efficiency, sustainability and viability of the full systems [13].

Within the different bioenergy technologies under development, those for the production of advanced biofuels such as liquid and gaseous biofuels for road transport, aviation and shipping (e.g. hydrogenated vegetable oil, cellulosic ethanol, Fisher Trop diesel, kerosene, alcohols, bio-methane, bio-CN and bio-LNG) represent a clear example of promising bioenergy applications. Supporting this statement, Wenger et al. [15], as a result of a large literature review on biorefineries research work, have recently claimed that biofuels drive the current biorefinery research. While conventional or first-generation biofuels are produced in biorefineries using food crops as feedstocks by mature and well-developed technologies, the second-generation or advanced biofuels production processes use non-edible biomass, such as dedicated energy crops, lignocellulosic residues and wastes as raw materials, and they are still not fully commercial. The challenge is to enlarge the utilization of these alternative biomass resources in a biorefinery based context to develop real advanced and integrated biorefineries, in which biofuels are produced together with a wide range of bioproducts for different markets. An interesting and promising approach to put into effect, in the context of biorefineries integration, is the combination of first- and second-generation (1G\&2G) bioethanol technologies by sharing the existing infrastructure and thus increasing the potential for energy optimization and products cost reduction [7]. The objective is to improve the process efficiency and economics of the biomass conversion and to get better economic and environmental performances than with standalone $2 \mathrm{G}$ facilities. For instance, corn ethanol industry has recently evaluated the potential of using corn kernel fiber to produce ethanol in existing corn mill ethanol plants in the so-called 1.5G technology and several process strategies are being developed [20]. For instance, the technology company D3MAX, formed by the Public-Private Partnership Bio-based Industry Initiative (BBI, https://www.bbi-europe.eu/about/about-bbi), has developed a process to convert corn fiber and residual starch generated in a corn dry mill ethanol plant into cellulosic ethanol. Figure 2 shows a schematic diagram describing the main stages of this technology, which combines conventional starch and cellulosic ethanol conversion processes [21]. The company D3MAX claims that this technology raises the overall ethanol yield of the plant by $11 \%$ and is advancing in the licensing and implementation in EEUU [22]. Another important advance in biorefinery integration is the case of sugarcane integrated biorefinery for the production of bioethanol and energy from sugarcane juice and bagasse, which has been demonstrated to have a high potential of economic viability [23]. The important role that the existing industrial infrastructure plays in the development of integrated biorefineries is highlighted by Hinsgsamer and Jungmeier [7], who state that the analysis of the possibilities for that integration will provide support to investors and decision-makers to invest and integrate resource-efficient biomass uses in a context of bioeconomy development. This opinion is also shared by Wenger and Stern [15], who assert that present agro and forest related industries will substantially contribute to make biorefineries a reality.

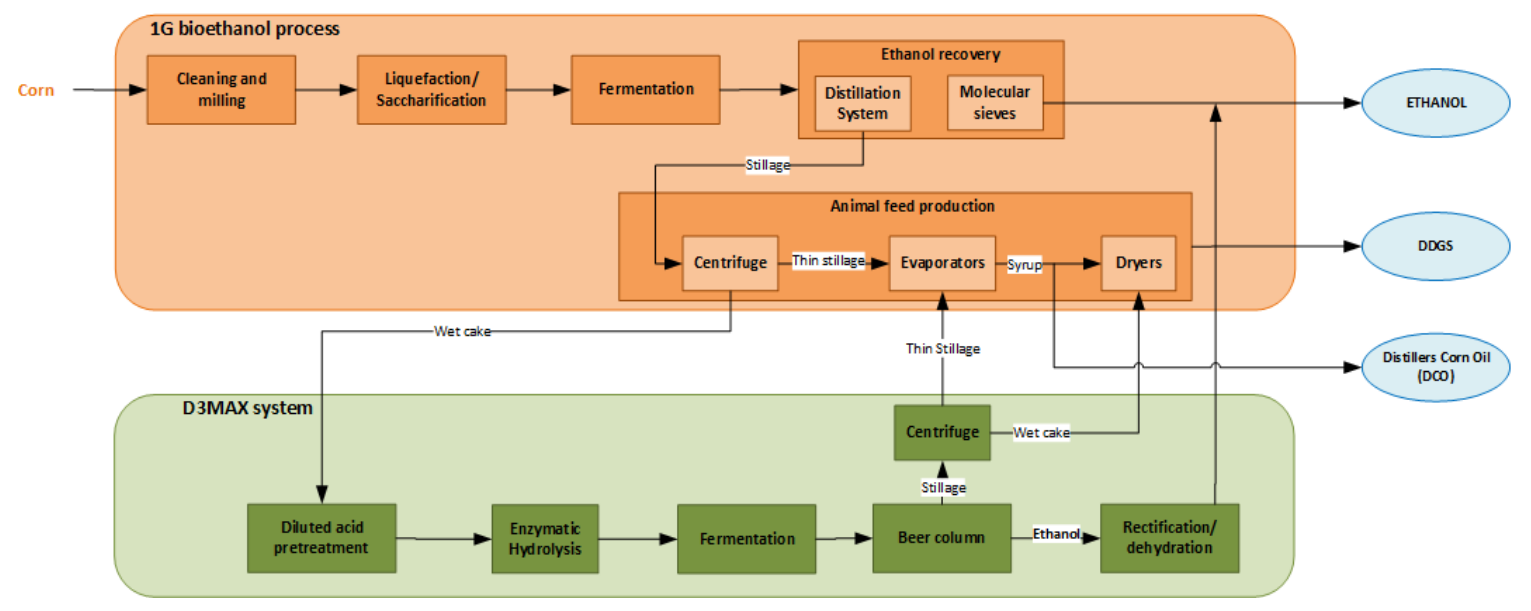

Fig. 2. Schematic diagram of D3MAX technology. Source: [21] 
In relation to the biorefineries technologies currently under development for the production of advanced biofuels, they comprise, in a general sorting, thermo-chemical and biochemical processes. Without any doubt, a future perspective of advanced biorefinery systems must consider the combination of one or more of the different approaches included in these two large groups. Thermochemical biomass conversion processes can be generally classified in torrefaction, pyrolysis, gasification and hydrothermal liquefaction, while biochemical pathways are based on the use of microorganisms and enzymes for biomass conversion to chemicals, materials or fuels. Nowadays, different bioenergy/biorefinery technologies are at various stages of development and so, it is difficult to identify the most promising ones. Many features such as i.e., feedstock availability and cost, technology readiness level (TRL), products/intermediates, and situation of emerging or existing markets for the products, among others, influence the real prospects for each one.

Regarding the status and main bottlenecks and barriers of each biorefinery conversion route, several recent papers and reports carried out by relevant organizations in the field have been published and research roadmaps have been defined $[13,14,24]$. It would be difficult to summarize herein this relevant information, so that to illustrate the progress achieved in the development of biorefinery systems and discuss the need for further research effort in this field, it may be interesting to focus on one of the most developed biorefinery systems so far for the production of advanced biofuels, that of lignocellulose-based biorefineries (LB). LBs use biochemical or thermochemical conversion routes, or a combination of both, to generate bioethanol, electricity, heat and bio-based chemicals using biomass from dedicated lignocellulosic crops or lignocellulosic residues.

LBs have been extensively investigated in the last decades and significant progress has been achieved in this field. Particularly in the case of cellulosic ethanol produced by biochemical conversion, the technological advances permitted in the past decade the construction of several pioneer facilities of $>10$ million gallons/year, turning cellulosic ethanol into the cellulosic biofuel deployed on the largest scale. [25]. Unfortunately, the global financial crisis started in 2008, the collapse in oil prices in 2014 and some drawbacks related to the expected anticipated technological readiness have somehow levelled off the prospects foreseen for this biofuel [26]. However, in spite of these "globalized" reasons, it is also acknowledged that still key technology-driven challenges need to be overcome to reach a cost- effective production. According to Lynd [26], strong investment in R\&D focused on innovation and novel processing models is required to achieve financial viability of cellulosic biofuels, including cellulosic ethanol.

The technical assessment and further development of innovative routes involves testing and demonstration, sustained by R\&D\&I, to demonstrate their effectiveness and contribute to eventually achieve the commercialization and application in the market. This scientific and technical effort will contribute to advance towards a knowledge-driven bioeconomy in the future and result in the development of new markets and competitiveness in different bioeconomy sectors.

Innovation on lignocellulose biorefinering

On the one hand, as biomass feedstock constitutes the starting point of all downstream processes in biorefinery, research and innovation in the field of primary biomass production has been identified as one of the key pillars to develop a feasible sustainable biorefinery-driven bioeconomy [27]. Research efforts need to be directed to the improvement of biomass yields per unit of land, while minimising negative environmental impacts through the optimization of water and nutrients efficiency. To this end, it appears crucial to advance in the knowledge of the metabolism, biochemistry and structure of the plant that will pave the way for the development of new varieties with enhanced processing characteristics. Advanced genetic engineering tools, as well as modern breeding techniques, show enormous potential to maximize biomass productivity and develop novel varieties suited to specific environments.

Specifically for the lignocellulosic biomass feedstocks, understanding the structure and interactions of the main components of plant cell wall (i.e., cellulose, hemicellulose and lignin), will help to develop and design lignocellulose materials that enable improved and cost-effective fractionation processes, aimed at extracting the largest possible quantity of valuable material. For instance, a modified lignocellulosic biomass composition with increased cellulose content and reduced lignin content is an interesting approach to enhance biomass properties, which in turn can imply a major impact on processing costs by, for example, decreasing the energy needed for pre-treatment and the enzyme requirements for downstream processing [13]. However, although this approach 
appears to be a good strategy to overcome biomass structure recalcitrance and it has been explored [27, 28], the molecular mechanisms regulating biomass components biosynthesis are not fully understood yet and further research progress is still required in this field.

On the other hand, lignocellulose biorefining research is needed to introduce innovations involving upstream and downstream technologies in both thermochemical and biochemical conversion pathways to enhance profitability, diminish risks and enlarge the value of co-products and biobased products (26).

In the development of thermochemical production systems, general challenges that hinder commercial deployment such as the lack of large scale demonstration of the technologies, comprising economic, technical and social aspects, and the quality of the end products, have been identified [14]. Specific research needs for each technology pathway are well presented in the document drawn up in the framework of the EERA Bioenergy Joint Programme, aimed at increasing the efficiency, sustainability and cost-competitive production of advanced biofuels and bioenergy carriers from biomass through thermochemical processing [13]. For example, in gasification, the most mature thermochemical process, the research topics identified are focused in broad terms on increasing feedstock flexibility by utilizing low-cost materials, improving gasifier performance, optimising product gas composition for downstream processing and developing innovative gasification processes such as molten bed gasification, reforming gasification and thermal and cold plasma gasification.

In the biochemical conversion pathway, based on the action of enzymes and fermentation processes using microorganisms, also general challenges and more specific R\&D needs have been extensively analysed by different research groups and scientific organizations [13,14,24,27,29]. As a first and essential step in biochemical processes, pretreatment for deconstruction and fractionation of biomass components needs further research and innovation work leading to improve the energy and water use efficiencies of the existing methodologies and develop new flexible processes capable of enhancing biological conversion effectiveness and product yield. Advanced and economically feasible extraction methods constitute an important goal in the future to produce new materials and chemicals [14]. Intensive research in process integration is also needed and innovative solutions are necessary for product purification. Moreover, the recovery of process side streams to obtain high value co-products has been highlighted as capital to achieve higher energy efficiencies and cost competitiveness for biofuel production in biorefinery schemes, so boosting the development of a circular economy. An example is the potential revalorization of the sugars and lignin streams generated in forest related- lignocellulosic raw material processing and pretreatment, as feedstocks to obtain a series of high-added value chemicals such as 5HMF, levulinic acid, furfurals, sugar alcohols, succinic acid, lactic acid and aromatics [30].

Another research and innovation priority in biochemical conversion concerns the search for new biocatalysts and microbial strains with improved features (tolerance, productivity and substrate range) for the development of advanced biochemical processes in biorefineries. Innovation in this field will come from the application of high-throughput screening and metagenomics techniques, genetic engineering, fermentation and biochemical reaction science, as well as the optimization of existing biotechnology tools to develop improved biocatalytic processes and fermentation strategies $[13,14]$. Synthetic biology will enable the production of new biocatalysts with improved performance under industrial conditions, while the development of new microbial systems by introducing novel metabolic pathways appears as a very promising tool to reduce the steps or units required in a biological process-based biorefinery. A good example is this last approach for the conversion of lignocellulosic biomass directly into biofuels is the development of Consolidated Bioprocessing, where a single microorganism features enzyme production, hydrolysis of polysaccharides, and fermentation of sugars within a single-unit operation, thus contributing to achieve a cost-efficient production of biomass-based fuels and chemicals [13]. Furthermore, it is important to highlight that to promote the biorefinery application potential in a future bioeconomy scenario, technology and full chain development of multi-stakeholder consortia is still necessary, according to the Biorefinering working group of the IEA [24]. The experts claim that joint international priorities and R\&D\&I programmes between industry, research institutes, universities, governmental bodies and NGOs are needed to boost innovation in biorefinering. Moreover, and as a result of the evolving character of bioeconomy development, an important issue to contemplate is that further growth in the biorefinery-based bio-economy will depend on the creation and expansion of markets for new co-products [20].

Finally, sustainability assessment of the whole value chain is needed to get an environmentally robust biorefinery-based bioeconomy. It must consider the economic, environmental and societal effects, as well as aspects as nutrient cycles, water management and food-feed-fuel-competition. To perform this analysis, suitable 
and practical assessment tools for an integrated sustainability evaluation are required [14]. To this respect, Life Cycle Analysis is a well-recognized and developed methodology that can be utilized to assess the global environmental performance of a product or process throughout its whole life cycle in a biorefinery, considering the economic, environmental and social impacts. Also, for a successful introduction of these new biorefinerybased products, it is essential to get consumers to have a positive perception of the benefits inherent to the biofuels and bioproducts generated in a biorefinery, as a part of a successful change to a real bioeconomy. Besides supporting policies to promote biorefineries from governmental bodies, it will be necessary to perform information and awareness campaigns to make the society understand that an important added-value of biorefinery-derived bioproducts and biofuels is the generation of valuable benefits from a socioeconomic and environmental point of view [31].

\section{Impact}

The use of biomass feedstocks to generate biofuels, bioproducts and bioenergy in a biorefinery concept will have a great social and economic impact at regional level through maximizing local resources to promote industry development, generate added-value and create employment, which in turn will result in the structuring of the territory. Added-value will be created through the whole value chain: from the biomass resource utilization (agricultural or industrial residues upgrading, development of biotechnology tools for plant breeding, new biomass dedicated crops, etc.), to the processes to produce bioenergy and bioproducts (advanced conversion technologies, use of process residual streams to generate new products in a circular economy, etc.). It means that apart from the value provided by the final product generated (bioenergy/bioproduct); the whole biomass to product productive process will be carried out contributing to connected sectors, i.e., agricultural and industrial sectors.

Finally and from a global perspective, the development of a bio-based economy will definitely help to face the energy, environmental and social challenges that a modern economy that assumes the objectives for a sustainable development (climate change mitigation, energy security, rural development, reindustrialization, poverty alleviation, etc.) involves.

\section{Conclusions}

Biorefieneries are a key pillar in the development of a future bioeconomy-based society. The conception of generating a large range of biofuels and bioproducts from a vast variety of biomass sources within a flexible and integrated biorefinery, opens the possibility to develop new and more sustainable processes and products that will eventually drive the transition from the current scenario of a mostly petroleum-based economy to a real bioeconomy. Significant progress has been achieved in the last decades in the assessment of biomass feedstocks production and supply as well as in the development of new and optimized technologies for the conversion of biomass materials into bio-based commodities through different technologies. Although some of the technologies have reached a development level very close to full commercialization, there is still a need of further research and innovation effort to overcome the drawbacks and barriers that all technologies still face. Finally, it is crucial to continue improving and developing tools to assure the sustainability of the full value chain, with special emphasis on the assessment of the socio-economic impacts that the biorefinery-based biofuels and bioproducts will have in the society.

\section{Conflict of interest}

There are no conflicts to declare.

\section{Acknowledgments}

The author acknowledges the financial support of the Ministry of Science and Innovation, Spain (project No. ENE2017-85819-C2-2-R).

\section{References}

[1] OECD. "The Bioeconomy of 2030", in The Bioeconomy to 2030: Designing a Policy Agenda, OECD Publishing, Paris, 2009, https://doi.org/10.1787/9789264056886-9-en (last accessed on 1 September 2020).

[2] European Commission. Communication from the Commission to the European Parliament, the Council, the European Economic and Social Committee and the Committee of the Regions: A Bioeconomy for Europe, COM, 
60, 2012. https://ec.europa.eu/research/bioeconomy/pdf/official-strategy en.pdf (last accessed on 11 September 2020).

[3] US Department of Energy. Energy Efficiency and Renewable Energy. Strategic plan for a thriving and sustainable bioeconomy. 2016, 48 p. https://www.energy.gov/sites/prod/files/2016/12/f34/ beto strategic plan december 2016 0.pdf. (last accessed on 10 September 2020).

[4] National Academies of Sciences, Engineering and Medicine Safeguarding the Bioeconomy. Washington, DC: The National Academies Press. 2020. https://doi.org/10.17226/25525 (last accessed on 5 September 2020).

[5] United Nations. Transforming our world: The 2030 Agenda for Sustainable Development. A/RES/70/1. 2019, 36 p. http://sustainabledevelopment.un.org. (last accessed on 9 September 2020).

[6] European Commission. Circular Economy Action Plan: For a Cleaner and more competitive Europe. 2020, https://ec.europa.eu/environment/circular-economy/pdf/new circular economy action plan.pdf. accessed on 21 September 2020).

[7] Hingsamer M, Jungmeier G Biorefineries. In: Lago C, Caldés N, Lechón Y (Eds.) The Role of Bioenergy in the Emerging Bioeconomy. Academic Press. Elsevier, 2018, pp. 180-221.

[8] IRENA. Global Bioenergy Supply and Demand Projections for the Year 2030. 2014, 78 p. https://www.irena.org/publications/2014/Sep/Global-Bioenergy-Supply-and-Demand-Projections-A-workingpaper-for-REmap-2030 (last accessed on 21 September 2020).

[9] Sanchez J, Curt MD, Robert N, Fernandez J. Biomass Resources. In: Lago C, Caldés N, Lechón Y (Eds.) The Role of Bioenergy in the Emerging Bioeconomy. Academic Press. Elsevier, 2018, pp. 25-98.

[10] European Parliament (2018). Directive (EU) 2018/2001 of the European Parliament and of the Council on the promotion of the use of energy from renewable sources. http://data.europa.eu/eli/dir/2018/2001/oj (last accessed on 21 September 2020).

[11] Perea-Moreno MA, Samerón-Manzano E, Perea-Moreno AJ. Biomass as Renewable Energy: Worldwide Research Trends. Sustainability 11 (2019), 863.

[12] Ahorsu R, Medina F, Constantí M. Significance and Challenges of Biomass as a Suitable Feedstock for Bioenergy and Biochemical Production: A Review. Energies 11 (2018), 3366.

[13] European Energy Research Alliance (EERA) Bioenergy. Strategic Research and Innovation Agenda (SIRA) 2020. (2020), 102 p, http://www.eera-bioenergy.eu/wp-content/uploads/pdf/ (last accessed on 25 September 2020)

[14] European Biorefinery Joint Strategic Research Roadmap. Star-COLIBRI project (www.star-colibri.eu). Strategic Targets for 2020 - Collaboration Initiative on Biorefineries, 2011, 68.

[15] Wenger J, Stern T. Reflection on the research on and implementation of biorefinery systems -a systematic literature review with a focus on feedstock. Biofuels, Bioproducts and Biorefinering 13 (2019), 1347-1364.

[16] Kamm B, Kamm M. Biorefineries - multiproduct processes. In: Ulber R, Sell D. (Eds.) White Biotechnology. Advances in Biochemical Engineering/Biotechnology, vol 105, Springer, Berlin, Heidelberg, 2007, 175-204.

[17] Cherubini F, Jungmeier G, Wellisch M, Willke T, Skiadas I, van Ree R, de Jong E. Toward a common classification approach for biorefinery systems. Biofuels, Bioproducts and Biorefinering 3 (2009), 534-546.

[18] Takkellapati S, Li T, Gonzalez M. An overview of biorefinery derived platform chemicals from a cellulose and hemicellulose biorefinery. Clean Technologies \& Environmental Policy 20 (2018), 1615-1630.

[19] Harmsen PFH, Hackmann MM, Bos HL. Green building blocks for bio-based plastics. Biofuels, Bioproducts and Biorefinering 8 (2014), 309-326.

[20] Awasthi MK, Sarsaiya S, Patel A, Juneja A, Singh RS, Yan B, Awasthi SK, Jain A, Liu T, Duan Y, Pandey A, Zhang $Z$, Taherzadeh MJ. Refining biomass residues for sustainable energy and bio-products: An assessment of technology, its importance, and strategic applications in circular bio-economy. Renewable and Sustainable Energy Reviews 127 (2020), 109876.

[21] Susmozas A, Martín-Sampedro R, Ibarra D, Eugenio ME, Iglesias R, Manzanares P, Moreno AD. Process Strategies for the Transition of $1 G$ to Advanced Bioethanol Production. Processes 8 (2020), 1310.

[22] D3MAX. D3MAX Technology. 2017. Available from: https://www.d3maxllc.com/technology. (last accessed on 1 October 2020).

[23] Vasconcelos MH, Mendes FM, Ramos L, Dias MS, Bonomi A, Jesus CD, Watanabe MD, Junqueira TL, Milagres AM, Ferraz A, dos Santos JC. Techno-economic assessment of bioenergy and biofuel production in integrated sugarcane biorefinery: Identification of technological bottlenecks and economic feasibility of dilute acid pretreatment. Energy 199 (2020), 117422.

[24] IEA Bioenergy Task 42. Technical, Economic and Environmental Assessment of Biorefinery Concepts. Developing a practical approach for characterization (2019), 55. 
[25] Lynd RL, Liang X, Biddy MJ, Allee A, Cai H, Foust T, Himmel ME, Laser MS, Wang M, Wyman CE. Cellulosic Ethanol: Status and Innovation. Current Opinion in Biotechnology 45 (2017), 202-211.

[26] Lynd RL, The grand challenge of cellulosic biofuels. Nature Biotechnology 35 (2017), 912-915.

[27] Vanholme B, Desmet T, Ronsse F, Rabaey K, Van Breusegem F, De Mey M, Soetaert W, Boerjan W. Towards a carbon-negative sustainable bio-based economy. Frontiers in Plant Science 4 (2013), 174.

[28] San Martín-Davison J, Ballesteros M, Manzanares P, Petit-Breuilh X, Vergara-Fernández A. Effects of temperature on steam explosion pretreatment of poplar hybrids with different lignin contents in bioethanol production. International Journal of Green Energy 12 (2015), 832-842.

[29] ETIP Bioenergy. Strategic Research and Innovation Agenda 2018.22018 , https://www.etipbioenergy.eu/about-ebtp/the-role-of-etip-bioenergy/strategic-research-innovation-agendasria. (last accessed on 5 October 2020).

[30] Kohli K, Prajapati R, Sharma BK. Bio-Based chemicals from renewable biomass for integrated biorefineries. Energies 12 (2019), 40.

[31] Brinkmana MLJ, Wickea B, Faaijb APC, van der Hilsta F. Projecting socio-economic impacts of bioenergy: Current status and limitations of ex-ante quantification methods. Renewable and Sustainable Energy Reviews 115 (2019), 109352. 